Check for updates

Cite this: Nanoscale Adv., 2019, 1, 1002

\title{
Colloidal hydroxyethyl starch for tumor-targeted platinum delivery $\dagger$
}

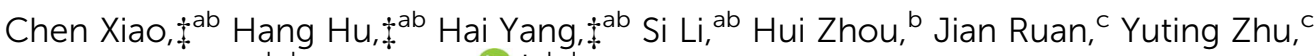 \\ Xiangliang Yang ${ }^{\text {abd }}$ and Zifu Li (iD *abde
}

Cis-platinum has been widely used as a first-line chemotherapy agent in clinics for more than 40 years. Although considerable efforts have been expended for developing platinum-based nano drug delivery systems (NDDS) to resolve the problems of low water solubility, short half-life, and severe side effects of cis-platinum, it remains challenging to apply these nanoplatforms to cancer treatments in clinics on account of the issues related to safety, complex fabrication procedures, and limited cellular uptake. Herein, we constructed a novel cis-platinum delivery system with hydroxyethyl starch (HES), which is a semisynthetic polysaccharide that has been used worldwide as colloidal plasma volume expanders (PVE) in clinics for several decades. By combining TEM, AFM, and DLS, we have found that HES particles are colloidal nanoparticles in solution, with diameters ranging from 15 to $40 \mathrm{~nm}$ as a function of molecular weight. We further revealed that HES adopted a hyperbranched colloidal structure with rather compact conformation. These results demonstrate that HES is a promising nanocarrier to deliver drug molecules. Taking advantage of the poly-hydroxyl sites of HES, we constructed a novel HES-based cisplatinum delivery nanoplatform. HES was directly conjugated with cis-platinum prodrug via an ester bond and decorated with an active targeting molecule, lactobionic acid (LA), contributing toward higher in vitro antitumor activity against hepatoma carcinoma cells as compared to cis-platinum. These results have significant implications for the clinically used plasma volume expander-HES and shed light on the clinical translation of HES-based nano drug delivery systems.

Received 5th October 2018 Accepted 23rd November 2018

DOI: $10.1039 / c 8 n a 00271 a$

rsc.li/nanoscale-advances agents-has excellent anticancer efficacy and non-cross drug resistance. However, the water solubility of cis-platinum is not appreciable, which hinders its cellular uptake and antitumor activity. It has also been reported that almost $65-98 \%$ of cisplatinum is preferentially combined with proteins in the plasm after intravenous administration. ${ }^{5}$ This protein combination process can further hinder cis-platinum from entering into cancer cells and reduce antitumor efficiency. This nonspecific combination can also affect the function of proteins and induce some serious systemic toxicity, such as nephrotoxicity, myelosuppression, and neurotoxicity. ${ }^{6}$ Therefore, developing platinum-based drugs with improved cellular uptake, higher antitumor efficacy, and reduced side effects is still a pressing unmet need..$^{7-11}$

With the development of nanotechnology, a series of nano drug delivery systems (NDDS) have been developed for cancer chemotherapy to simultaneously prolong drug circulation, enhance tumor accumulation, increase specific cancer cell uptake, improve antitumor efficiency, and reduce side effects. ${ }^{12}$ Nanoparticles with good biocompatibility can stealthily circulate in the blood and selectively accumulate at the tumor site by the enhanced permeation and retention (EPR) effect or active tumor targeting with specific ligand modifying the surface of the nanoparticles..$^{13} \mathrm{~A}$ specific ligand can improve the receptor- 
mediated endocytosis by targeting receptors overexpressed by cancer cells. ${ }^{14}$ The loaded drugs are encapsulated or conjugated within the nanoparticles to achieve superior water solubility and sustained or stimulated drug release. To take advantage of these properties of nanoparticles, several NDDS have been designed to deliver cis-platinum, such as micelles, ${ }^{15-17}$ dendrimers, ${ }^{18,19}$ nanoscale coordination polymers, ${ }^{20,21}$ nanogels, ${ }^{22}$ and inorganic nanoparticles. ${ }^{23,24}$ However, it remains challenging to apply these nanoplatforms to clinical cancer treatment on account of the following reasons. First, there are certain safety concerns about most nanoplatforms that are undegradable. The accumulation of these materials in the human body may induce toxicity in normal tissues. ${ }^{25,26}$ Second, the fabrication process requires complex procedures, tedious chemical purifications, and/or harsh conditions that can result in reduced efficacy or increased costs. Third, these stealth nanoparticles capable of long circulation are still hindered by compromised cellular uptake, resulting in limited antitumor efficacy. Therefore, constructing a nanoplatform with biodegradable materials and tumor-specific ligands for cis-platinum delivery by simple and robust procedures can facilitate the clinical translation of cis-platinum-loaded NDDS.

Hydroxyethyl starch (HES) is a semisynthetic polysaccharide and used as one of the first-line colloidal plasma volume expanders (PVE) in clinics for decades, showing commendable physiochemical properties, biocompatibility, and biodegradability. As an FDA-approved biocompatible polymer, HES has also been used widely in drug delivery systems to improve drug solubility and stability, extend half-life time, and achieve passive cancer targeting. Taking advantage of the abundant hydroxyl groups on the polysaccharide, HES can conjugate with drug molecules, specifically targeting ligands or hydrophobic chains. To improve the water solubility and antitumor efficacy, HES has been successfully conjugated with drug molecules, such as doxorubicin, ${ }^{27,28} 5$-Fu, ${ }^{29} 10$-CPT, ${ }^{30,31}$ paclitaxel, ${ }^{32}$ docetaxel, ${ }^{33}$ and methotrexate ${ }^{34}$ for cancer chemotherapy. Hence, employing HES to conjugate with cis-platinum could be a promising way to potentiate the anticancer efficacy of cisplatinum. Most importantly, developing a cis-platinum delivery platform based on HES has promising clinical application prospects because the utilization of HES has been approved by numerous clinical practices.

Herein, we constructed a novel cis-platinum delivery system with clinically used HES. First, to conjugate with HES, cisplatinum was oxidized into $\mathrm{Pt}(\mathrm{Iv})$ and functionalized with a carboxyl group, as previously reported. ${ }^{35}$ Then, by two simple esterification reactions, the cis-platinum prodrug, $\mathrm{Pt}-\mathrm{COOH}(\mathrm{Iv})$, and the active targeting molecule, lactobionic acid (LA), were linked with HES via ester bonds. Finally, after this simple fabrication process, LA-HES-Pt was obtained. The water solubility of cis-platinum can be significantly improved after conjugation with HES. According to our previous reports, HES is a nanoparticle that can passively target a tumor site by the EPR effect. Moreover, LA can actively target hepatoma cells with a high-level expression of ASGPR, promoting cellular endocytosis. ${ }^{14}$ After entering into cancer cells, conjugated $\mathrm{Pt}(\mathrm{Iv})$ is reduced to Pt(II) because of GSH, ascorbic acid, thioalcohol, and low pH. Hence, cis-platinum can be released, leading to DNAinduced apoptosis. ${ }^{15}$ This simple fabrication process and FDAapproved raw materials (cis-platinum, HES, and LA) endow LA-HES-Pt with high druggability and significant clinical translation potential. To the best of our knowledge, this is the first study in which HES has been used to deliver cis-platinum in cancer chemotherapy.

\section{Materials and methods}

\section{Materials}

HES 25/0.5 (molecular weight: $25 \mathrm{kDa}$; molar substitution of hydroxyethyl: 0.5), 70/0.5, 130/0.4, 200/0.5, and 480/0.5 were gifts obtained from Wuhan HUST Life Science \& Technology Co., Ltd. (Wuhan, China). cis-Diammineplatinum dichloride (cis-platinum, 65\%), hydrogen peroxide solution $\left(\mathrm{H}_{2} \mathrm{O}_{2}, 30 \%\right)$, $N$-ethyl- $N^{\prime}$-(3-dimethylaminopropyl) carbodiimide hydrochloride (EDCI, 98\%), 4-dimethylaminopyridine (DMAP, 99\%), and succinic anhydride (99\%) were purchased from Aladdin Reagent Inc. (Shanghai, China). LA (97\%) was purchased from Macklin Reagent Inc. (Shanghai, China). Cyanine5 mono NHS ester (Cy5-NHS, 95\%) was purchased from Lumiprobe (USA). All the other chemicals were of the analytical grade and used as received. Human liver cancer cell line, HepG-2, and murine breast cancer cell line, 4T1, were obtained from Shanghai Institutes for Biological Sciences.

\section{General measurements}

The ${ }^{1} \mathrm{H}$ NMR spectra were measured by a $600 \mathrm{MHz}$ NMR spectrometer (Bruker, Ascend ${ }^{\mathrm{TM}} 600 \mathrm{MHz}$ ) at room temperature. Fourier-transform infrared (FT-IR) spectra were recorded by an FT-IR spectrometer (Bruker, Vertex 70) with an ATR accessory. The UV spectra were measured by a UV spectrophotometer (Persee, TU-1901). Transmission electron microscope (TEM, Hitachi, HT7700) and atomic force microscope (AFM, Bruker, MultiMode V8) images were used to characterize the morphology of HES. A dynamic light scattering analyzer (Malvern, Zetasizer Nano ZS90) was used for the measurement of the colloidal properties of HES. Gel permeation chromatography (GPC) was used to study the molecular weight and conformation of HES. X-ray diffraction (XRD) spectra were measured by an XRD diffractometer (PANalytical, Empyrean). Atomic absorption spectrometer (AAS, Perkin Elmer, AA 300) and inductively coupled plasma optical emission spectrometry (ICP-OES, Thermo, iCAP 7000) were used for platinum quantification in platinum conjugates and cellular uptake, respectively. A microplate reader (Thermo, Multiskan) was used to perform 3(4,5-dimethyl-2-thiazolyl)-2,5-diphenyl-2- $H$-tetrazolium bromide (MTT) assays. Flow cytometer (Berkman Coulter, CytoFLEX) and confocal microscope (Olympus, FV1000) were used to analyze the cellular uptake of Cy5-labeled HES conjugates.

\section{TEM characterization}

HES samples $\left(200 \mu \mathrm{g} \mathrm{mL}^{-1}\right)$ were dripped onto the copper mesh, dried in air, and stained with $0.2 \%$ phosphotungstic acid 
for $30 \mathrm{~s}$ and characterized with TEM at $80 \mathrm{KV}$ acceleration voltage. HES-Pt and LA-HES-Pt samples were dripped on the copper mesh, dried in air, and directly observed with TEM.

\section{AFM characterization}

HES samples were dissolved in deionized water and diluted to $20 \mu \mathrm{g} \mathrm{mL}{ }^{-1}$. The diluted solutions were dripped with $10 \mu \mathrm{L}$ on fresh mica, dried in air, and characterized by AFM in the ScanAsyst mode.

\section{GPC characterization}

Different HES samples dissolved in an acetate buffer with a concentration of $10 \mathrm{mg} \mathrm{mL}^{-1}$ were characterized by GPC. The mobile phase was acetic acid/sodium acetate buffer and the flow rate was $0.5 \mathrm{~mL} \mathrm{~min}^{-1}$. The column temperature was controlled at $35{ }^{\circ} \mathrm{C}$. The wavelength of the laser detector was set at $658.0 \mathrm{~nm}$.

\section{Synthesis of $\boldsymbol{c}, \boldsymbol{t}, \boldsymbol{c}$-[ $\left[\mathrm{PtCl}_{2}(\mathrm{OH})_{2}\left(\mathrm{NH}_{3}\right)_{2}\right]$}

Briefly, cis-platinum $(1.00 \mathrm{~g}, 3.33 \mathrm{mmol})$ was suspended in deionized water $(25.0 \mathrm{~mL})$. To the solution, $\mathrm{H}_{2} \mathrm{O}_{2}(35.0 \mathrm{~mL}, 30.0$ $\mathrm{mmol}$ ) was added and the resulting mixture was stirred at $50{ }^{\circ} \mathrm{C}$ for $1 \mathrm{~h}$. Then, the precipitate was isolated by filtration and sequentially washed with water, ethanol, and ether. The obtained precipitate was dried under vacuum to give a yellow powder (816 mg; yield: $73.3 \%$ ).

\section{Synthesis of $c, t, c-\left[\mathrm{PtCl}_{2}(\mathrm{OH})\left(\mathrm{O}_{2} \mathrm{CCH}_{2} \mathrm{CH}_{2} \mathrm{CO}_{2} \mathrm{H}\right)\left(\mathrm{NH}_{3}\right)_{2}\right]$}

Succinic anhydride $(150.1 \mathrm{mg}, 1.5 \mathrm{mmol})$ was added to a solution of $c, t, c-\left[\mathrm{PtCl}_{2}(\mathrm{OH})_{2}\left(\mathrm{NH}_{3}\right)_{2}\right](500 \mathrm{mg}, 1.5 \mathrm{mmol})$ in DMSO (40 $\mathrm{mL}$ ) and the resulting mixture was stirred at room temperature for $12 \mathrm{~h}$. Then, the reaction mixture was precipitated with ether. The precipitate was isolated by centrifugation, washed with acetone and ether thrice, and dried under vacuum to give a yellow powder (590 mg; yield: 90.6\%).

\section{Synthesis of HES-Pt}

The synthesized Pt-COOH $(100 \mathrm{mg}, 0.23 \mathrm{mmol})$ was dissolved in DMF (16 mL). To this solution, HES (100 mg; glucose unit: 0.6 mmol), EDCI (220.1 mg, $1.15 \mathrm{mmol})$ and DMAP ( $71.0 \mathrm{mg}, 0.58$ $\mathrm{mmol}$ ) were added and the resulting mixture was stirred at $45{ }^{\circ} \mathrm{C}$ for $48 \mathrm{~h}$. Then, the reaction mixture was dialyzed against water for 3 days and lyophilized (102 mg; yield: $51.0 \%$ ).

\section{Synthesis of LA-HES-Pt}

LA (100 mg, $0.28 \mathrm{mmol})$ was dissolved in DMF $(20 \mathrm{~mL})$. To the solution, HES-Pt (100 mg; glucose unit: $0.52 \mathrm{mmol})$, EDCI (268.4 $\mathrm{mg}, 1.4 \mathrm{mmol}$ ), and DMAP $(85.5 \mathrm{mg}, 0.7 \mathrm{mmol})$ were added and the resulting mixture was stirred at $45^{\circ} \mathrm{C}$ for $48 \mathrm{~h}$. Then, the reaction mixture was dialyzed against deionized water for 3 days and lyophilized (109 mg; yield: 54.5\%). Based on the ${ }^{1} \mathrm{H}$ NMR spectrum, we calculated that there are around $104 \mathrm{LA}$ molecules on each HES nanoparticle.
The platinum loading content (DLC) of HES-Pt and LA-HESPt were determined by an atomic absorption spectrometer, which was calculated as

$$
\text { DLC }(\%)=\frac{\mathrm{Wt}(\text { loaded Pt })}{\mathrm{Wt}(\text { Pt-loaded conjugates })} \times 100 \%
$$

where Wt (loaded Pt) is the weight of the loaded platinum and Wt (Pt-loaded conjugates) is the weight of Pt-loaded conjugates. From the drug loading content, we calculated that there are around 23 cisplatin molecules in LA-HES-Pt.

\section{Cellular uptake}

To investigate the cellular uptake mechanism of LA-modified HES (LA-HES), ASGPR-overexpressed HepG-2 cells were selected, whereas 4T1 cells without ASGPR expression were selected as the negative control. HES and LA-HES were labeled by fluorochrome Cy5 for confocal imaging and flow cytometry analysis. Briefly, HepG-2 and 4T1 cells were seeded into glass bottom cell culture dishes at $5 \times 10^{4}$ cells per well. After incubating with HES-Cy5 or LA-HES-Cy5 $\left(200 \mu \mathrm{g} \mathrm{mL}{ }^{-1}\right)$ for $12 \mathrm{~h}$, the medium was removed and the cells were washed with PBS buffer ( $\mathrm{pH}$ 7.4, $6.7 \mathrm{mmol} \mathrm{L}^{-1}$ ) thrice. Then, the cells were fixed with $4 \%$ paraformaldehyde and stained with DAPI for confocal imaging. To investigate the competitive inhibition effect of LA on the cellular uptake of LA-HES-Cy5, HepG-2 cells were preincubated with LA ( $\left.500 \mu \mathrm{g} \mathrm{mL}{ }^{-1}\right)$ for $4 \mathrm{~h}$ followed by incubation with HES-Cy5 or LA-HES-Cy5 $\left(200 \mu \mathrm{g} \mathrm{mL}^{-1}\right)$ for $12 \mathrm{~h}$. Then, the cells were fixed with $4 \%$ paraformaldehyde and stained with DAPI for confocal imaging. The cellular uptakes of HES-Cy5 and LA-HES-Cy5 were also quantified by flow cytometry.

The cellular uptakes of HES-Pt and LA-HES-Pt were quantified by ICP-OES. Briefly, HepG-2 cells were seeded into 12-well plates at a cell density of $2 \times 10^{5}$ cells per well. After incubating the cells with cis-platinum, Pt-COOH, HES-Pt, and LA-HES-Pt for $6 \mathrm{~h}$, the medium was removed and the cells were washed with PBS thrice. Then, the cells were harvested and counted. The cell suspensions were digested with a mixture of nitric acid $(65-68 \%, 2.0 \mathrm{~mL})$ and perchloric acid $(70-72 \%, 0.15 \mathrm{~mL})$ at $320^{\circ} \mathrm{C}$ for $30 \mathrm{~min}$. After cooling to room temperature, the above solutions were diluted to $10 \mathrm{~mL}$ with deionized water and measured by ICP-OES at $214.4 \mathrm{~nm}$.

\section{Biocompatibility assessment}

The murine fibroblast cell line, 3T3, was used to evaluate the biocompatibility of HES. Briefly, 3T3 was seeded into a 96-well plate with a cell density of $5 \times 10^{3}$ per well. After culturing overnight, different HES samples were incubated with 3 T3 cells at concentrations ranging from $0.1 \mu \mathrm{g} \mathrm{mL} \mathrm{mL}^{-1}$ to $1000 \mu \mathrm{g} \mathrm{mL} \mathrm{L}^{-1}$ for $24 \mathrm{~h}$. Then, MTT assays were used to determine the cell viability, as previously reported. Cells incubated only with the medium were used as the reference for $100 \%$ viability.

\section{In vitro antitumor activity}

MTT assays were used to evaluate the in vitro cytotoxicity of cisplatinum, Pt-COOH, HES-Pt, and LA-HES-Pt against human hepatoma cells, HepG-2. Briefly, HepG-2 cells were seeded into 
96-well plates with a cell density of $5 \times 10^{3}$ per well. After culturing overnight, 4-well cells were incubated with different materials at various concentrations. After $24 \mathrm{~h}$ incubation, MTT assays were used to determine the cell viability as previously reported. Cells incubated only with the medium were used as the reference for $100 \%$ viability.

\section{Statistical analysis}

All the data were presented as the mean value \pm standard deviation (SD). Statistical analysis was performed by the Statistical Product and Service Solutions (SPSS) program with independent samples $T$-test. The statistical significance was established at $p<0.05$. ${ }^{*} p<0.05,{ }^{* *} p<0.01,{ }^{* *} p<0.001$.

\section{Results and discussion}

Derived from waxy maize that contains more than 95\% amylopectin, HES is a semisynthetic polysaccharide and has been used as the first-line colloidal PVE for several decades in clinics. ${ }^{36}$ HES can be categorized into various classes based on its molecular weight, molar substitution of hydroxyethyl, and hydroxyethylation substitution pattern (C2/C6 ratio). ${ }^{37}$ These parameters affect the endogenous $\alpha$-amylase, which selectively cleaves $\alpha$-(1,4)-glycosidic bonds but not the branching $\alpha-(1,6)$ glycosidic bonds and mediates the degradation of HES in blood, thereby determining the in vivo pharmacokinetics of HES and facilitating the tailoring of the in vivo fates of HES by simply modulating these parameters. Although safety concerns have been raised for acute kidney injury and increased risk of mortality when HES is administered to seriously ill patients requiring acute volume resuscitation (particularly to patients with severe sepsis and those in intensive care), ${ }^{38-41}$ HES has extremely low immunogenicity, presumably owing to the common structural features between HES and glycogen, both of which are branched polysaccharides. ${ }^{42}$ A good manufacturing practice, high water solubility, tailorability, biocompatibility, biodegradability, and well-defined and proven in vivo safety features not only facilitate HES to be widely applied in clinics as PVE, ${ }^{36,43-45}$ cryoprotectant, ${ }^{\mathbf{4 6 - 4 9}}$ organ preservation solutions, ${ }^{50}$ granulocytes separation solutions, ${ }^{51-53}$ and cell culture medium, ${ }^{54}$ but also to be a promising drug carrier with promising clinical translation potential. ${ }^{55-57}$ To this end, various drug delivery systems have been recently developed based on HES, including HES and small drug conjugates; ${ }^{27-30,32,34,58}$ HES and protein conjugates; ${ }^{56,59}$ HES-derived nanocolloidosomes; ${ }^{60}$ and HES-based nanoparticles, ${ }^{61-67}$ capsules, ${ }^{68-71}$ and hydrogels. ${ }^{72-75}$ Although HES has been applied in clinics for over 50 years, its fundamental conformation, structure, and morphology are largely unknown. To retain the branched structure of amylopectin, hydrodynamic diameters around dozens of nanometers have been frequently measured in HES solutions with DLS. ${ }^{28,34,58,59,76}$ TEM and AFM imaging has revealed that HES exhibits a colloidal structure in self-assembled nanoparticles $^{67,77}$ and conjugates. ${ }^{60}$ Nonetheless, the conformation and structure of a single HES particle remains an enigma. Without such information, correlating the structure of HES with clinical uses and safety concerns is impossible, and the rational clinical applications of HES and clinical translations of HESbased drug delivery systems will be limited. Initially, the conformation and structure of single HES, with different molecular weights, will be systematically scrutinized by a combination of DLS, TEM, AFM, GPC, and NMR.

\section{HES conformation}

To comprehensively understand the conformation of HES, HES with different molecular weights, namely, $480 \mathrm{kDa}, 200 \mathrm{kDa}$, $130 \mathrm{kDa}, 70 \mathrm{kDa}$, and $25 \mathrm{kDa}$, have been studied by a combination of GPC and DLS. As shown in Table 1, the average molecular weight of HES 480/0.5, HES 200/0.5, HES 130/0.4, HES 70/0.5, and HES 25/0.5 measured by GPC are $426.1 \times 10^{3}$, $206.1 \times 10^{3}, 134.0 \times 10^{3}, 92.4 \times 10^{3}$, and $34.2 \times 10^{3} \mathrm{~g} \mathrm{~mol}^{-1}$, respectively. The polydispersity values of five HES samples are between 1.95 and 3.88, indicating a relatively wide molecular weight distribution. Fig. S1† shows that the GPC spectra of different HES samples are significantly overlapped with each other, suggesting that HES samples have a relatively wide molecular weight distribution. These results are similar to the others. $^{76,78}$ Considering the production practice of HES, the observed results in the GPC are reasonable as HES is retained by the membrane separation technique.

The conformational coefficient $\alpha$ is a good indicator of the conformation of macromolecules and can be obtained with the following equation:

$$
R_{\mathrm{g}}=k M^{\alpha}
$$

taking the logarithm of both the sides of eqn (1):

$$
\lg R_{\mathrm{g}}=\lg k+\alpha \lg M
$$

where $R_{\mathrm{g}}$ is the radius of gyration, $k$ is the proportionality constant, and $M$ is the molar mass of the individual polymer molecule. Therefore, $\alpha$ can be obtained by measuring $R_{\mathrm{g}}$ and molar mass. Fig. S2 $\uparrow$ shows the double logarithmic plot of HES 480/0.5, HES 200/0.5, and HES 130/0.4. A linear fit can be applied to each sample to calculate $\alpha{ }^{61,79}$ As shown in Table 1, the $\alpha$ values of HES 480/0.5, HES 200/0.5, and HES 130/0.4 are $0.46,0.42$, and 0.42 , respectively. Due to the bad data quality of HES 25/0.5 and HES 70/0.5, the $\alpha$ value of HES 25/0.5 and 70/0.5 could not be determined. It is reported that $\alpha$ is equal to 1 for rigid rods, 0.5-0.6 for random coils, and 0.33 for hard spheres. ${ }^{\mathbf{8 0}, 81}$ The $\alpha$ values of our HES samples are slightly lower than that of random coils, indicating that HES has a relatively compact conformation rather than a linear one. Our results are in good agreement with those reported by others. ${ }^{79}$ Further, $\rho$ ratio is another indicator for the conformational quantification of macromolecules. The $\rho$-ratio is known as the ratio of the gyration radius to the hydrodynamic radius $\left(R_{\mathrm{g}} / R_{\mathrm{h}}\right)$; these radii can be measured by GPC and DLS, respectively. As shown in Table 2, the $\rho$-ratio values of our HES samples are between 1.04 and 1.13. It was reported that the $\rho$-ratio is equal to 0.778 for hard spheres, 0.977 for dendrimers, 1.225 for a hyper-branched polymer, and 1.73 for a random coil of linear macromolecules 
Table 1 GPC characterizations of $\mathrm{HES}^{a}$

\begin{tabular}{|c|c|c|c|c|}
\hline Sample & $M_{\mathrm{w}}\left(\times 10^{3} \mathrm{~g} \mathrm{~mol}^{-1}\right)$ & $\begin{array}{l}\text { Polydispersity } \\
\left(M_{\mathrm{w}} / M_{\mathrm{n}}\right)\end{array}$ & $\begin{array}{l}\text { Conformational } \\
\text { coefficient } \alpha\end{array}$ & $\begin{array}{l}\text { RMS radius } \\
(\mathrm{nm})\end{array}$ \\
\hline HES $480 / 0.5$ & 426.1 & 3.77 & 0.46 & 19.6 \\
\hline HES $130 / 0.4$ & 134.0 & 1.95 & 0.42 & 8.1 \\
\hline HES $70 / 0.5$ & 92.4 & 2.77 & - & 8.4 \\
\hline HES $25 / 0.5$ & 34.2 & 2.38 & - & - \\
\hline
\end{tabular}

Table 2 DLS characterizations and $\rho$-ratio of $\mathrm{HES}^{a}$

\begin{tabular}{lllll}
\hline Sample & $D_{\mathrm{h}}$ & PDI & $R_{\mathrm{h}}(\mathrm{nm})$ & $\begin{array}{l}\rho \text {-ratio } \\
\left(R_{\mathrm{g}} / R_{\mathrm{h}}\right)\end{array}$ \\
\hline HES 480/0.5 & $35.0 \pm 1.6$ & $0.412 \pm 0.024$ & 17.5 & 1.12 \\
HES 200/0.5 & $20.6 \pm 0.6$ & $0.227 \pm 0.005$ & 10.3 & 1.13 \\
HES 130/0.4 & $15.5 \pm 0.7$ & $0.118 \pm 0.054$ & 7.8 & 1.04 \\
HES 70/0.5 & $15.4 \pm 0.6$ & $0.308 \pm 0.023$ & 7.7 & 1.09
\end{tabular}

${ }^{a} D_{\mathrm{h}}$, hydrodynamic diameter. $R_{\mathrm{h}}$, hydrodynamic radius. $R_{\mathrm{g}}$, radius of gyration.

in a $\theta$-solvent. ${ }^{82}$ The $\rho$-ratio values of our HES samples are between dendrimers and hyper-branched polymers, indicating that HES has a relatively compact conformation. ${ }^{42}$ Meanwhile, the ${ }^{1} \mathrm{H}$ NMR spectra of HES were investigated to confirm that HES is a hyperbranched polymer, and there are many hydroxyl sites that can be modified (Fig. S3 and S4 $\dagger$ ). Collectively, the ${ }^{1} \mathrm{H}$ NMR spectra, $\alpha$, and $\rho$-ratio corroborate that HES can adopt a compact conformation.

\section{HES morphology}

The size distributions of HES in an aqueous solution have been reported in previous studies. ${ }^{34,76,77}$ However, the morphology of HES is largely unknown, particularly that of a single HES particle. TEM and AFM have been widely employed to directly characterize the morphology of macromolecules. ${ }^{7,83}$ Here, TEM and AFM were utilized to characterize the morphology of HES 480/0.5, HES 200/0.5, and HES 130/0.4. HES was negatively stained by phosphotungstic acid and characterized by TEM at a low acceleration voltage $(80 \mathrm{kV})$. Fig. 1A shows that HES particles are nearly spherical (white) for each single HES. Moreover, all the HES samples have a spherical shape. The AFM images consistently show that HES are nearly spherical particles (Fig. 1C). These results are consistent with the relatively compact conformation of HES and indicate that the HES nanoparticles are intrinsic. The diameters of HES determined by TEM and AFM are in accordance with those determined by DLS (Fig. 1B and D and Table 2). To be specific, the diameters of HES 130/0.4, 200/0.5, and 480/0.5 determined by TEM characterization are $14.74 \pm 2.01 \mathrm{~nm}, 20.64 \pm 2.03 \mathrm{~nm}$, and $28.75 \pm$ $4.79 \mathrm{~nm}$, respectively (Fig. 1B). The AFM results are consistent with the TEM results (Fig. 1D). The hydrodynamic diameter $\left(D_{\mathrm{h}}\right)$ values of HES 130/0.4 and 200/0.5 are 15.5 $\pm 0.7 \mathrm{~nm}$ and $20.6 \pm$ $0.6 \mathrm{~nm}$, respectively, which are similar to the TEM and AFM results. However, the $D_{\mathrm{h}}$ value of HES $480 / 0.5$ is $35.0 \pm 1.6 \mathrm{~nm}$, which is slightly larger than those in the TEM and AFM results. This may be attributed to the significant swelling effect of HES 480/0.5 in the aqueous solution (Table 2). Further, we found that the hydrodynamic diameter of HES decreased with increasing concentration, suggesting the hydrodynamic diameter of HES is dependent on the osmotic pressure and implying that HES particles are soft nanoparticles that can be squeezed by osmotic stress (Fig. S5 $\dagger$ ). The DLS, TEM, and AFM images corroborate the fact that the size of HES increases with its molecular weight, and the diameters of HES 480/0.5, HES 200/ 0.5 , and HES $130 / 0.4$ are in the range of $10-40 \mathrm{~nm}$, which is beneficial for prolonged in vivo circulation and passive tumor targeting via the EPR effect. ${ }^{28,76}$ The diameters of HES with different molecular weights and degrees of substitution were also measured by DLS, AFM, and TEM in previous studies. ${ }^{28,34,60,66,76}$ However, integrating GPC, DLS, and TEM with AFM for uncovering the structure and morphologies of HES has been seldom reported. The combination of various advanced characterization techniques facilitates the complete appreciation of HES. The revealed colloidal structure of HES might correlate with acute kidney injury when administered as PVE in clinics, as branched HES might get stuck in the glomeruli of kidneys. Nonetheless, more systematic studies are required, particularly for undertaking clinical trials. Taken together, the GPC, DLS, TEM, and AFM results corroborate the colloidal structure of HES.

\section{Pt delivery system based on HES nanoparticles}

Based on the understanding that HES particles are intrinsic nanoparticles with a suitable size for in vivo circulation and passive tumor targeting, we constructed a novel prodrug of cisplatinum further modified with LA, which can specifically bind to the ASGPR overexpressed on the surfaces of hepatoma cells, HepG-2. ${ }^{60}$ There are many advantages of this drug delivery system (LA-HES-Pt). First, HES has excellent solubility and good biocompatibility and biodegradability, which can improve cisplatinum solubility and stability. ${ }^{31,33,63,84}$ Second, LA-HES-Pt can attain passive cancer targeting due to the EPR effect of HES, and it can also be specifically taken up by hepatoma cells via ASGPR-LA-mediated endocytosis pathways. Third, HES, cisplatinum, and LA have been approved for clinical practice, which endows LA-HES-Pt with high druggability. ${ }^{64}$ Last, but not the least, platinum is a high-atomic-number element, which 
A.

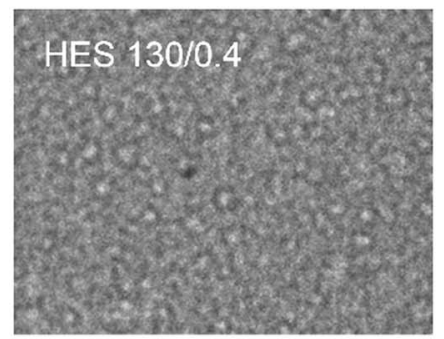

B.

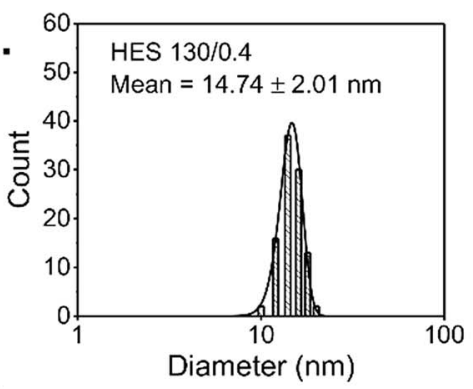

C.

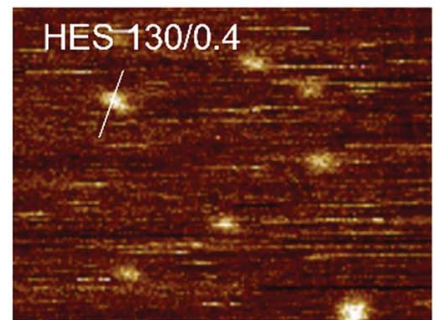

D.

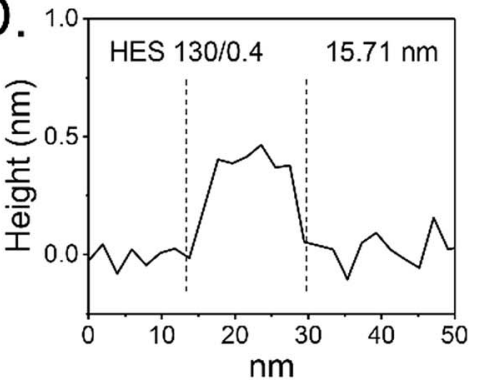

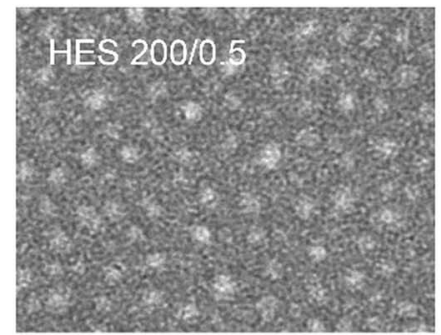
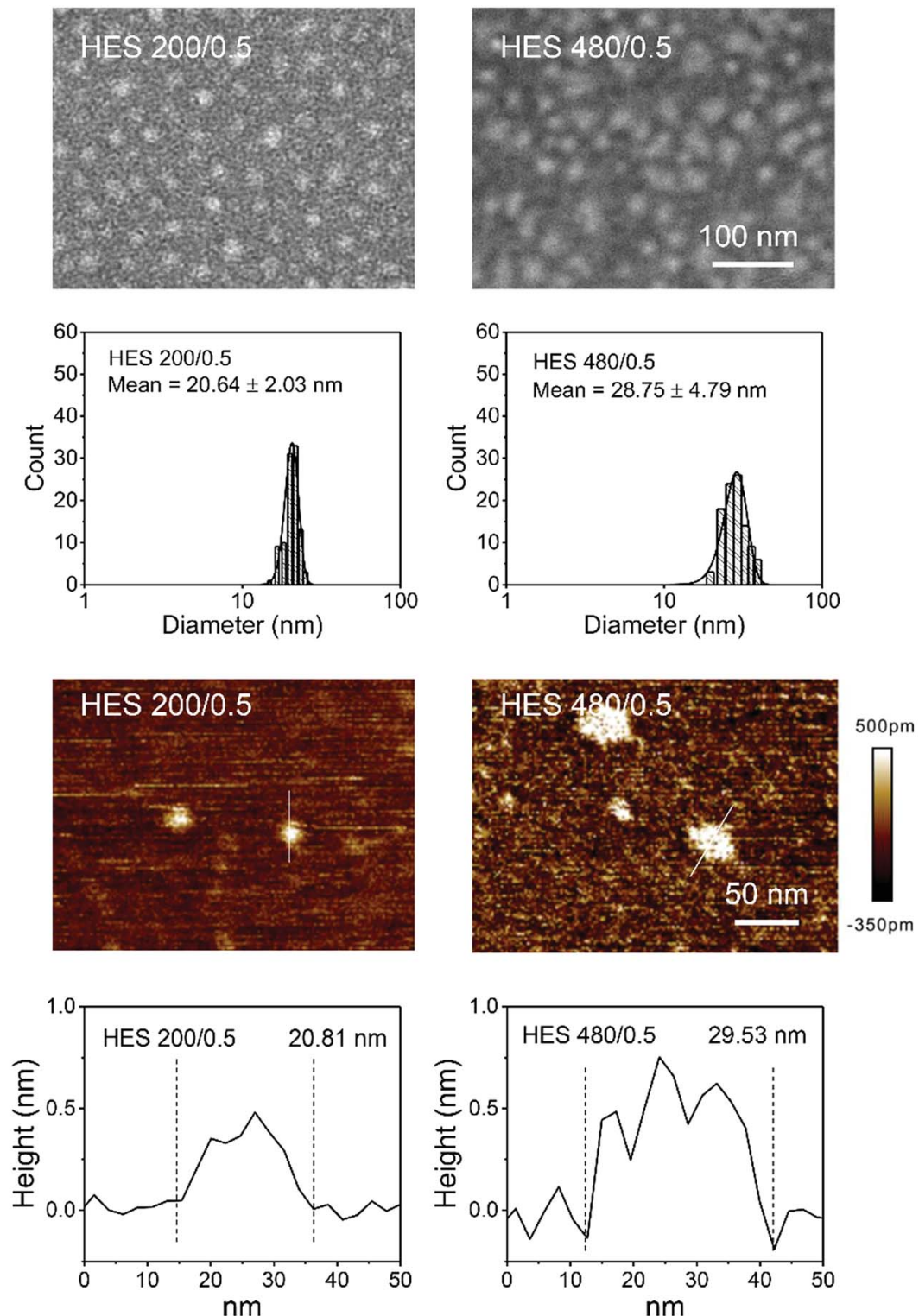

Fig. 1 Morphology of HES 130/0.4, HES 200/0.5, and HES 480/0.5. (A) TEM images of HES. The scale bar is $100 \mathrm{~nm}$ and applied for all the TEM images. (B) Statistical analysis of TEM images. (C) AFM images of HES. The scale bar is $50 \mathrm{~nm}$ and applied for all the AFM images. (D) AFM height profiles of HES with different molecular weights.

facilitates the direct detection of HES under TEM observations without the need for staining. As shown in Fig. 2A, LA-HES-Pt was synthesized through three simple steps. $\mathrm{Pt}-\mathrm{COOH}$, a ramification of cis-platinum, was firstly prepared according to a previously method reported. ${ }^{35}$ Then, HES-Pt was synthesized via an esterification reaction between the carboxyl group of Pt$\mathrm{COOH}$ and hydroxyl group of HES. Finally, HES-Pt was modified with galactose moieties via an esterification reaction between the carboxyl group of LA and hydroxyl group of HES. Several studies have shown that HES 200/0.5 exhibits prolonged in vivo circulation and excellent tumor accumulation. ${ }^{28,30}$ Here, HES $200 / 0.5$ was selected as the starting material to synthesize LAHES-Pt. The successful synthesis of HES-Pt and LA-HES-Pt was confirmed by ${ }^{1} \mathrm{H}$ NMR, FT-IR, and UV (Fig. 2B, C and S6A-C $\dagger$ ).
The ${ }^{1} \mathrm{H}$ NMR spectra of $\mathrm{Pt}-\mathrm{COOH}$ show the characteristic signals of succinyl at 2.50-2.62 ppm (Fig. S6A $\dagger$ ) and the FT-IR spectra of $\mathrm{Pt}-\mathrm{COOH}$ are in accordance with those reported in the literature ${ }^{15,85}$ (Fig. S6B $\dagger$ ), suggesting the successful synthesis of Pt-COOH. The ${ }^{1} \mathrm{H}$ NMR spectra of HES-Pt also show the characteristic signals of succinyl (Fig. 2B) and the FT-IR spectra of HES-Pt show the characteristic band of an ester bond at $1718 \mathrm{~cm}^{-1}$ (Fig. 2D), indicating that $\mathrm{Pt}-\mathrm{COOH}$ is successfully conjugated onto HES through the ester bond. When compared with HES-Pt, the characteristic signal of LA at $4.50 \mathrm{ppm}$ appears in the ${ }^{1} \mathrm{H}$ NMR spectra of LA-HES-Pt (Fig. 2C), suggesting the successful synthesis of LA-HES-Pt. Collectively, ${ }^{1} \mathrm{H}$ NMR and FTIR effectively demonstrate the successful synthesis of HES-Pt and LA-HES-Pt. The platinum loading content of HES-Pt and 
A.

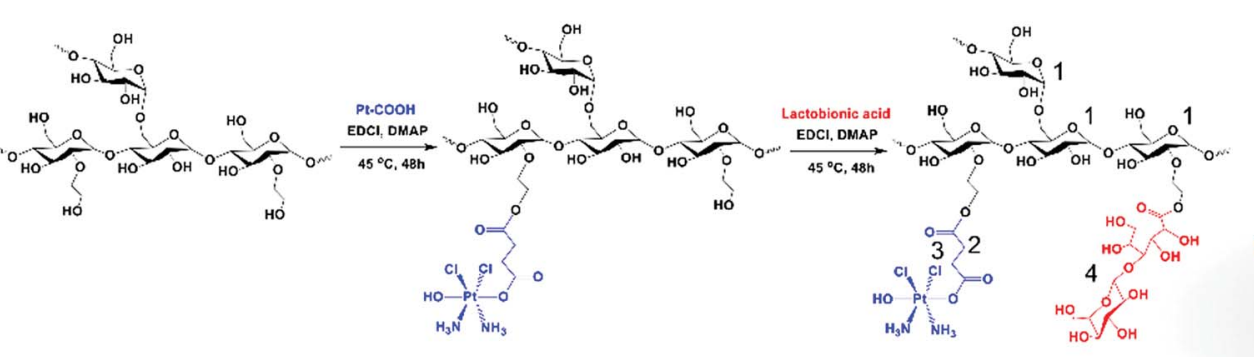

HES HES-Pt

LA-HES-Pt

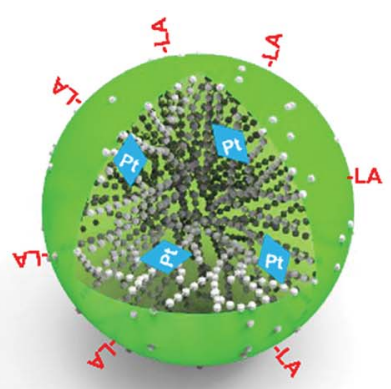

B.

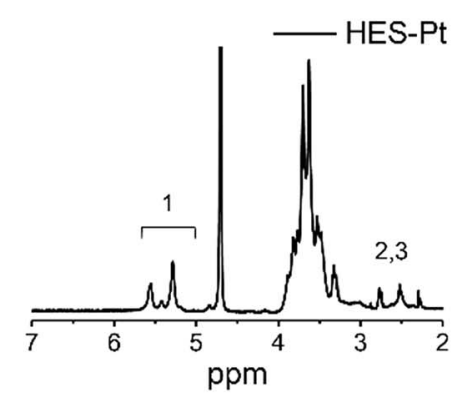

E.

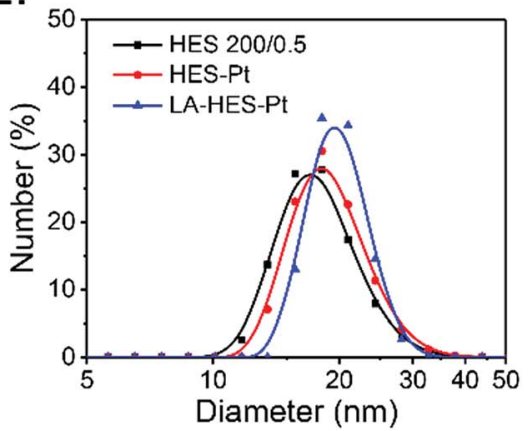

C.

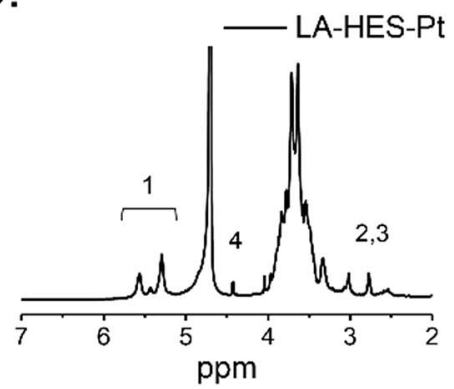

$\mathrm{F}$.

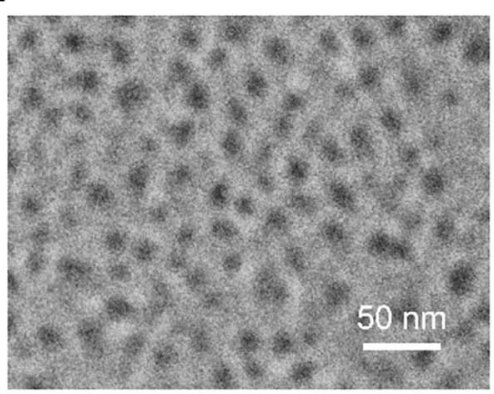

D.

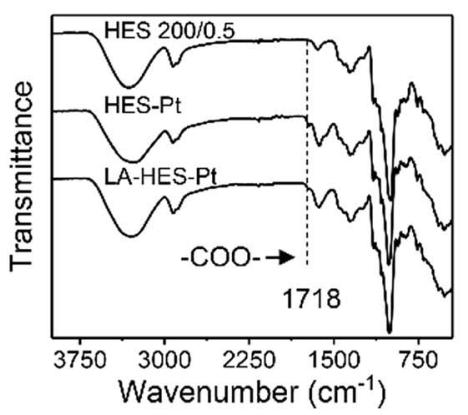

G.

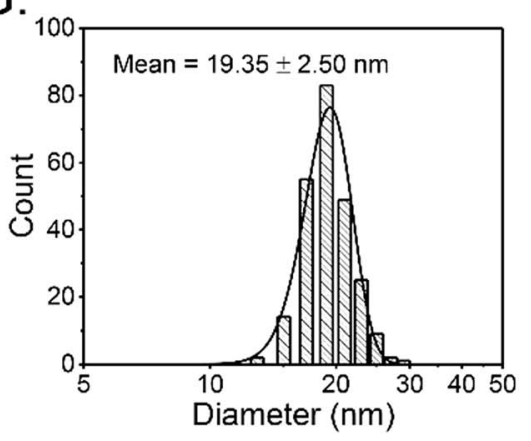

Fig. 2 Synthesis and characterization of HES-Pt and LA-HES-Pt. (A) Synthesis scheme of HES-Pt and LA-HES-Pt. (B) ${ }^{1} \mathrm{H}$ NMR spectra of HES-Pt. (C) ${ }^{1} \mathrm{H}$ NMR spectra of LA-HES-Pt. (D) FT-IR spectra of HES, HES-Pt, and LA-HES-Pt. (E) Size distribution of HES, HES-Pt, and LA-HES-Pt measured by DLS. (F) TEM image of LA-HES-Pt. Scale bar: $50 \mathrm{~nm}$. (G) Size distribution of LA-HES-Pt determined from the TEM image (F).

LA-HES-Pt are $6.4 \%$ and $2.6 \%$, respectively, as determined by the atomic absorption spectrometer.

The size distribution of HES, HES-Pt, and LA-HES-Pt are measured by DLS (Fig. 2E); their hydrodynamic diameters are $18.09 \pm 3.89,19.25 \pm 3.94$, and $20.00 \pm 2.94 \mathrm{~nm}$, respectively (Table 3), indicating the insignificant size changes after Pt$\mathrm{COOH}$ and LA conjugation. Due to the high atomic number of platinum, platinum can effectively absorb the incident electrons in TEM imaging, resulting in high contrast with HES.

Table 3 DLS and drug loading characteristics of HES, HES-Pt, and LAHES-Pt

\begin{tabular}{llll}
\hline Sample & Diameter $(\mathrm{nm})$ & Zeta potential $(\mathrm{mV})$ & $\begin{array}{l}\text { Drug loading } \\
(\%)\end{array}$ \\
\hline HES & $18.09 \pm 3.87$ & $1.35 \pm 2.03$ & - \\
HES-Pt & $19.25 \pm 3.94$ & $-1.31 \pm 0.04$ & 6.4 \\
LA-HES-Pt & $20.00 \pm 2.94$ & $-2.06 \pm 0.57$ & 2.6
\end{tabular}

After coupling with platinum, the resultant conjugate can be easily characterized by TEM without staining. HES-Pt based on HES 130/0.4, HES 200/0.5, and HES 480/0.5 were characterized by TEM (Fig. S7†). HES-Pt exhibits nearly spherical morphology and the size increases with the molecular weight of HES, which is consistent with the results of HES characterized by TEM and AFM (Fig. 1). Further, the TEM image of LA-HES-Pt shows that LA-HES-Pt exhibits nearly spherical nanoparticles (Fig. 2F). Moreover, the XRD spectra of HES, HES-Pt, and LA-HES-Pt show an amorphous characteristic, indicating that the morphology of those samples characterized by TEM and AFM exhibit single molecular, and not crystalline, morphology (Fig. S6D †). The average diameter of LA-HES-Pt determined from the TEM image is $19.35 \pm 2.50 \mathrm{~nm}$ (Fig. 2G), which is consistent with the hydrodynamic diameter determined by DLS. The zeta potentials of HES, HES-Pt, and LA-HES-Pt in PBS buffer are $1.35 \pm 2.03$, $-1.31 \pm 0.04$, and $-2.06 \pm 0.57 \mathrm{mV}$, respectively, indicating that 
they are neutral. Collectively, these results confirm that HES-Pt and LA-HES-Pt are intrinsic nanoparticles, like HES.

To investigate the cellular uptake of HES and LA-modified HES (LA-HES), ASGPR-overexpressed HepG-2 cells were chosen, and 4T1 cells without ASGPR expression were chosen as the negative control. Fluorescent dye Cy5 was conjugated onto HES and LA-HES for confocal imaging and flow cytometry analysis. Human liver cancer HepG-2 cells with ASGPR overexpression were incubated with Cy5-labeled HES and LA-HES for $12 \mathrm{~h}$. As expected, an increased Cy5 signal was observed in the LA-HES-Cy5 group when compared with that in HES-Cy5 by confocal laser scanning microscopy (CLSM) (Fig. 3A). This indicated that increased HES was taken into HepG-2 cells after modification with LA. Meanwhile, this uptake could be inhibited by the preincubation with additional free LA by competition uptake (Fig. 3A). Quantitative flow cytometry measurement further revealed that the cellular uptake of HES was enhanced by 4.1 times by the modification of LA molecules (Fig. 3B and C), while the endocytosis of HES-Cy5 was not affected by the preincubation of free LA with HepG-2 cells. These results suggest that the uptake of LA-HES-Cy5 by HepG-2 cells is via the ASGPRLA-mediated endocytosis pathway. The cellular uptake of LAHES-Cy5 is similar to that of HES-Cy5 on ASGPR-negative 4T1 cells (Fig. S8A-C $\dagger$ ), further confirming the ASGPR-LA-mediated endocytosis of LA-HES-Cy5 on HepG-2 cells.

Since it is reported that the modification of hydrophilic HES inhibits the cellular uptake of drug conjugates, ${ }^{28,34}$ several targeting molecules have been used to improve the cellular uptake of HES-based drug delivery systems, such as iRGD-HES, ${ }^{67}$ FAHES (folic acid), ${ }^{86}$ and Gal-HES (galactosamine). ${ }^{60}$ Further, it has been reported that the cellular uptake of nanoparticles modified by LA (galactose moiety) is high on ASGPR-positive cancer cells via ligand-receptor-mediated endocytosis. ${ }^{\mathbf{1 4}}$ Herein, we successfully conjugated LA with HES and investigated its cellular uptake properties. Taken together, these results show that LA modification can promote the cellular uptake of HES, particularly on ASGPR-overexpressed cells due to ASGPR-LA-mediated endocytosis.

To study the cellular uptake of HES-Pt and LA-HES-Pt, the intracellular platinum content was measured by ICP-OES (Fig. 4A). HepG-2 cells were incubated with cis-platinum, PtCOOH, HES-Pt, and LA-HES-Pt $\left(10 \mu \mathrm{g} \mathrm{mL}{ }^{-1}\right.$ of platinum $)$ for $6 \mathrm{~h}$, and the intracellular platinum content was determined thereafter. To be specific, the intracellular platinum content of cisplatinum, Pt-COOH, HES-Pt, and LA-HES-Pt determined by ICP-OES are $0.02 \pm 0.01 \mu \mathrm{g}, 0.01 \pm 0.01 \mu \mathrm{g}, 0.06 \pm 0.01 \mu \mathrm{g}$, and $0.26 \pm 0.01 \mu \mathrm{g}$ for every $10^{5}$ cells, respectively (Fig. $\left.4 \mathrm{~A}\right)$. Pt$\mathrm{COOH}$ exhibits a reduced cellular uptake as compared to cisplatinum, which can ascribe to the enhanced hydrophilicity of $\mathrm{Pt}-\mathrm{COOH}$, preventing the interaction between $\mathrm{Pt}-\mathrm{COOH}$ and cell membranes. ${ }^{16}$ HES-Pt exhibits enhanced cellular uptake as compared to both $\mathrm{Pt}-\mathrm{COOH}$ and cis-platinum, implying the advantage of conjugation with HES. LA-HES-Pt exhibits the highest cellular uptake, with intracellular platinum content 15.6 times higher than that of cis-platinum and 4.3 times higher than that of HES-Pt. These results surprised us with a significant improvement in the platinum uptake for 15.6 times when compared with that of cis-platinum. When compared with the previously reported platinum drug delivery systems in which platinum uptake was improved by 9.8 times by micelles ${ }^{15}$ and
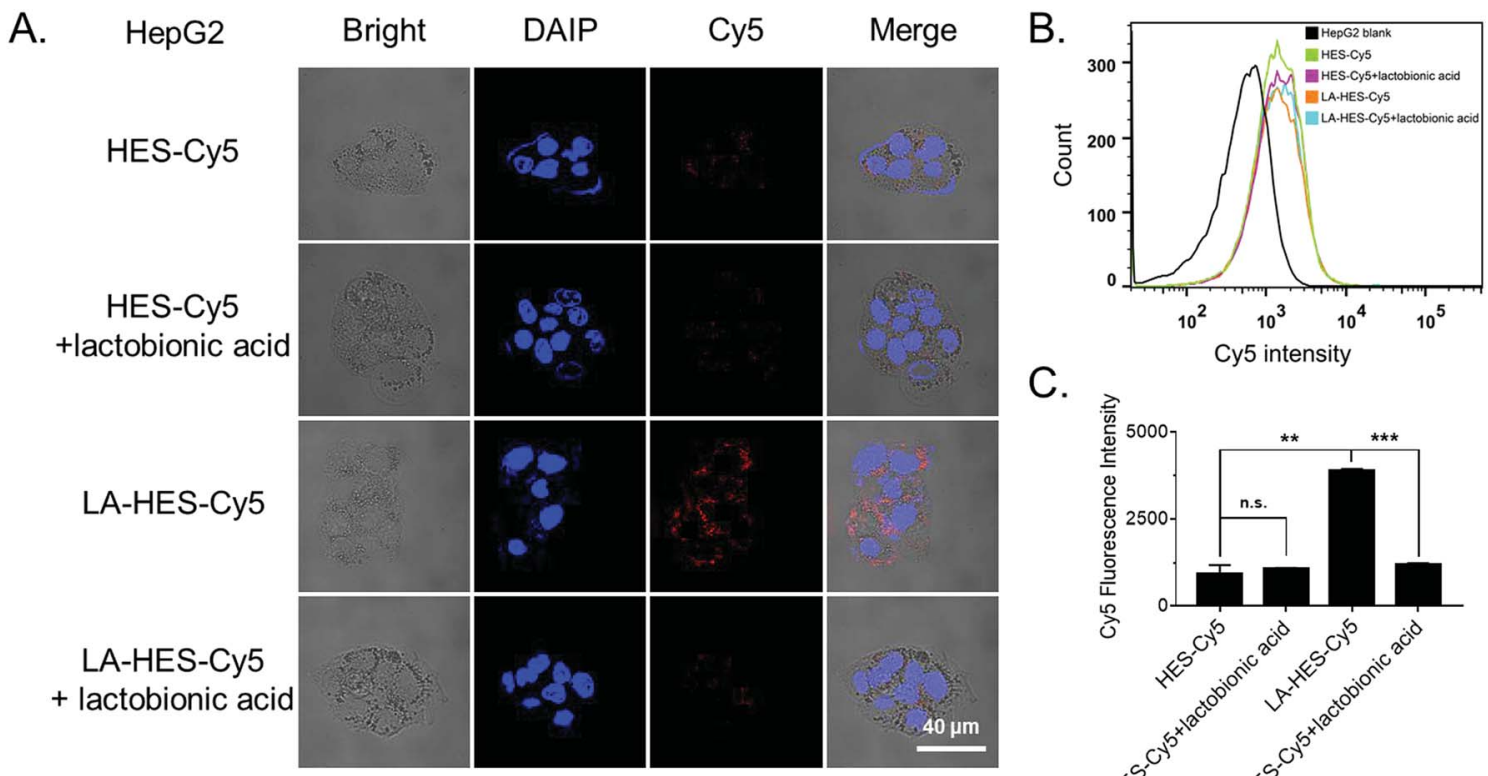

C.

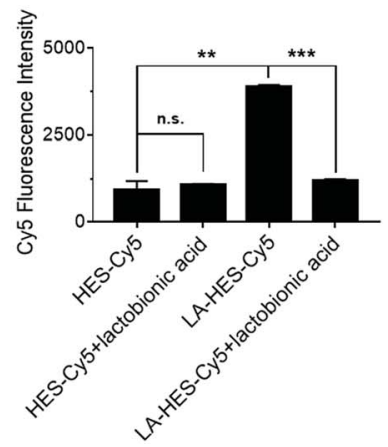

Fig. 3 Cellular uptake of HES-Cy5 and LA-HES-Cy5. (A) CLSM images of HepG-2 cells incubated with HES-Cy5 and LA-HES-Cy5 for 12 h, and HepG-2 cells preincubated with $500 \mu \mathrm{g} \mathrm{L}{ }^{-1}$ LA for $4 \mathrm{~h}$ followed by incubation with HES-Cy 5 and LA-HES-Cy 5 for $12 \mathrm{~h}$. The scale bar is $40 \mu \mathrm{m}$, applicable for all the images. (B) Flow cytometry analysis of HepG-2 cells incubated with HES-Cy5 and LA-HES-Cy5 for 12 h, and HepG-2 cells preincubated with $500 \mu \mathrm{g} \mathrm{L}{ }^{-1}$ LA for $4 \mathrm{~h}$ followed by incubation with HES-Cy5 and LA-HES-Cy5 for 6 h. (C) Mean fluorescence intensity determined by flow cytometry. ${ }^{*} p<0.05,{ }^{*} p<0.01,{ }^{* * *} p<0.001$, n.s. implies not significant. Data are represented as mean \pm SD ( $n=3$ ). 
A.

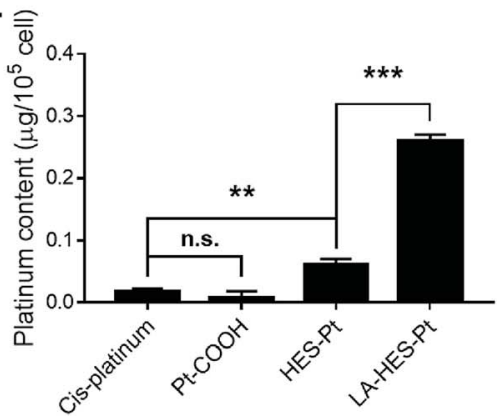

B.

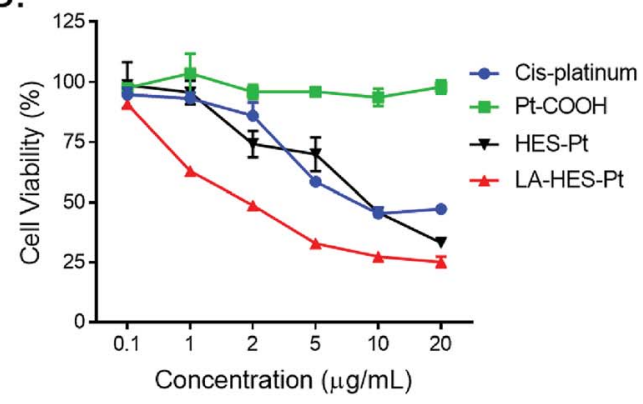

Fig. 4 Cellular uptake and in vitro cytotoxicity of LA-HES-Pt. Cellular uptake of cis-platinum, Pt-COOH, HES-Pt, and LA-HES-Pt in HepG-2 cells after incubation for $6 \mathrm{~h}$ with $10 \mu \mathrm{g} \mathrm{mL} \mathrm{m}^{-1}$ platinum concentration (A); in vitro cytotoxicity of cis-platinum, Pt-COOH, HES-Pt, and LA-HES-Pt against HepG-2 cells after incubation for $24 \mathrm{~h}$ (B). $* p<0.05, * *<0.01, * * * p<0.001$. n.s. implies not significant. Data are represented as mean \pm $\mathrm{SD}(n=3)$.

8.3 times by cationic lipid-assisted nanoparticles respectively, ${ }^{15}$ our results have shown the best cellular uptake efficiency.

The in vitro cytotoxicity values of HES-Pt and LA-HES-Pt against HepG-2 cells were finally evaluated by MTT assays (Fig. 4B). Cis-platinum, HES-Pt, and LA-HES-Pt exhibit cytotoxicity in a dose-dependent manner. LA-HES-Pt exhibits the highest cytotoxicity against HepG- 2 cells, with $\mathrm{IC}_{50}$ value that is 5.3-fold lower than that of cis-platinum and 4.4-fold lower than that of HES-Pt (Fig. S10 and Table S2 $\dagger$ ). To be specific, the $\mathrm{IC}_{50}$ values of cis-platinum, HES-Pt, and LA-HES-Pt were $11.34 \mu \mathrm{g}$ $\mathrm{mL}^{-1}, 9.40 \mu \mathrm{g} \mathrm{mL}^{-1}$, and $2.14 \mu \mathrm{g} \mathrm{mL}^{-1}$, respectively. Pt-COOH shows no cytotoxicity by MTT assay. Meanwhile, the biocompatibility of HES is also confirmed with MTT assay against murine fibroblast 3T3 cells (Fig. S9†).

Although several platinum drug delivery systems have been developed, only a few of these reported systems are more efficient than the cis-platinum system. ${ }^{15}$ It is mainly on the account of limited cellular uptake. Herein, our results have indicated that LA-HES-Pt have the highest cytotoxicity to HepG-2 cells. This can be ascribed to the efficient cellular uptake by ASGPRLA-mediated endocytosis (Fig. 4A). The platinum conjugated on LA-HES-Pt was reduced to cis-platinum by $\mathrm{GSH}$, ascorbic acid, thioalcohol, and low $\mathrm{pH}$ after entering into the cell, leading to DNA-induced apoptosis. ${ }^{15}$ HES-Pt also exhibits enhanced cellular uptake as compared to cis-platinum, but the cytotoxicity of HES-Pt is similar to cis-platinum, which may be ascribed to the insufficient intracellular Pt release of HES-Pt. ${ }^{15,16}$ Due to this limited cellular uptake, $\mathrm{Pt}-\mathrm{COOH}$ exhibits minimal cytotoxicity, which is also consistent with previous reports. ${ }^{15}$ When compared with previous reports, our results also show the best in vitro anti-hepatoma efficiency for platinum drug delivery systems. Taken together, based on our rational design, the in vitro antitumor activity of LA-HES-Pt against HepG-2 cells is significantly enhanced when compared with cis-platinum.

\section{Outlook and concluding remarks}

In summary, a novel cis-platinum delivery nanoplatform, LAHES-Pt, is constructed based on clinically used colloidal PVEs, namely, HES, to enhance the cellular uptake and cytotoxicity of cis-platinum. GPC, DLS, TEM, and AFM corroborate that HES particles are spherical. In vitro experiments verified that LAHES-Pt can actively target HepG- 2 cancer cells with a highlevel expression of ASGPR and promote cellular endocytosis to exert better antitumor effects than cis-platinum. Remarkably, the intracellular platinum content increases 15.6 times and $\mathrm{IC}_{50}$ decreases 5.3-folds for LA-HES-Pt when compared with cisplatinum. By revealing the structure of clinically used PVE, namely, HES, this study has significant clinical implications, paving the road for clinical translations of HES-based NDDS. Since HES, cis-platinum, and LA have been approved for clinical practice, the reported LA-HES-Pt has significant clinical translation potential and warrants further in vivo investigations.

\section{Conflicts of interest}

There are no conflicts to declare.

\section{Acknowledgements}

This work was financially supported by grants from National Key Research and Development Program of China (2018YFA0208900), National Basic Research Program of China (2015CB931802), National Science Foundation of China (Grant No. 81627901, 81473171 and 31700867), PCSIRT (Grant No. IRT13016), and Scientific Research Foundation of Huazhong University of Science and Technology (Grant No. 3004170130). We also thank the HUST Analytical and Testing Center for allowing us to use its facilities.

\section{References}

1 B. Rosenberg, L. Van Camp and T. Krigas, Nature, 1965, 205, 698-699.

2 L. Kelland, Nat. Rev. Cancer, 2007, 7, 573-584.

3 B. Surnar, K. Sharma and M. Jayakannan, Nanoscale, 2015, 7, 17964-17979.

4 A. Ummat, O. Rechkoblit, R. Jain, J. R. Choudhury, R. E. Johnson, T. D. Silverstein, A. Buku, S. Lone, 
L. Prakash, S. Prakash and A. K. Aggarwal, Nat. Struct. Mol. Biol., 2012, 19, 628-632.

5 R. C. DeConti, B. R. Toftness, R. C. Lange and W. A. Creasey, Cancer Res., 1973, 33, 1310-1315.

6 J. R. Yachnin, I. Wallin, R. Lewensohn, F. Sirzén and H. Ehrsson, Cancer Lett., 1998, 132, 175-180.

7 Z. Guo, Y. Zou, H. He, J. Rao, S. Ji, X. Cui, H. Ke, Y. Deng, H. Yang, C. Chen, Y. Zhao and H. Chen, Adv. Mater., 2016, 28, 10155-10164.

8 Y. Wang, Y. Deng, H. Luo, A. Zhu, H. Ke, H. Yang and H. Chen, ACS Nano, 2017, 11, 12134-12144.

9 T. Yang, H. Ke, Q. Wang, Y. a. Tang, Y. Deng, H. Yang, X. Yang, P. Yang, D. Ling, C. Chen, Y. Zhao, H. Wu and H. Chen, ACS Nano, 2017, 11, 10012-10024.

10 T. Yang, L. Liu, Y. Deng, Z. Guo, G. Zhang, Z. Ge, H. Ke and H. Chen, Adv. Mater., 2017, 29, 1700487.

11 S. Ye, J. Rao, S. Qiu, J. Zhao, H. He, Z. Yan, T. Yang, Y. Deng, H. Ke, H. Yang, Y. Zhao, Z. Guo and H. Chen, Adv. Mater., 2018, 30, 1801216.

12 Q. Sun, Z. Zhou, N. Qiu and Y. Shen, Adv. Mater., 2017, 29, 1606628-1606636.

13 D. Li, Y. Ma, J. Du, W. Tao, X. Du, X. Yang and J. Wang, Nano Lett., 2017, 17, 2871-2878.

14 K. Na, K.-H. Park, S. W. Kim and Y. H. Bae, J. Controlled Release, 2000, 69, 225-236.

15 H. Xiao, R. Qi, S. Liu, X. Hu, T. Duan, Y. Zheng, Y. Huang and X. Jing, Biomaterials, 2011, 32, 7732-7739.

16 H. Xiao, H. Song, Q. Yang, H. Cai, R. Qi, L. Yan, S. Liu, Y. Zheng, Y. Huang, T. Liu and X. Jing, Biomaterials, 2012, 33, 6507-6519.

17 M. Li, Z. Tang, S. Lv, W. Song, H. Hong, X. Jing, Y. Zhang and X. Chen, Biomaterials, 2014, 35, 3851-3864.

18 H.-J. Li, J.-Z. Du, X.-J. Du, C.-F. Xu, C.-Y. Sun, H.-X. Wang, Z.-T. Cao, X.-Z. Yang, Y.-H. Zhu, S. Nie and J. Wang, Proc. Natl. Acad. Sci. U. S. A., 2016, 113, 4164-4169.

19 H.-J. Li, J.-Z. Du, J. Liu, X.-J. Du, S. Shen, Y.-H. Zhu, X. Wang, X. Ye, S. Nie and J. Wang, ACS Nano, 2016, 10, 6753-6761.

20 W. Zhang and C.-H. Tung, ACS Appl. Mater. Interfaces, 2017, 9, 8547-8555.

21 Y. Yang, L. Xu, W. Zhu, L. Feng, J. Liu, Q. Chen, Z. Dong, J. Zhao, Z. Liu and M. Chen, Biomaterials, 2018, 156, 121133.

22 H. Zhao, J. B. Xu, J. S. Wan, S. A. Geng, H. Li, X. L. Peng, Q. W. Fu, M. He, Y. B. Zhao and X. L. Yang, Nanoscale, 2017, 9, 5859-5871.

23 G.-F. Luo, W.-H. Chen, Q. Lei, W.-X. Qiu, Y.-X. Liu, Y.-J. Cheng and X.-Z. Zhang, Adv. Funct. Mater., 2016, 26, 4339-4350.

24 J. Xu, Y. Kuang, R. Lv, P. Yang, C. Li, H. Bi, B. Liu, D. Yang, Y. Dai, S. Gai, F. He, B. Xing and J. Lin, Biomaterials, 2017, 130, 42-55.

25 K. Knop, R. Hoogenboom, D. Fischer and U. S. Schubert, Angew. Chem., Int. Ed., 2010, 49, 6288-6308.

26 M. Barz, R. Luxenhofer, R. Zentel and M. J. Vicent, Polym. Chem., 2011, 2, 1900-1918.

27 Y. Zhu, X. Yao, X. Chen and L. Chen, J. Appl. Polym. Sci., 2015, 132, 42778.
28 H. Hu, Y. Li, Q. Zhou, Y. Ao, C. Yu, Y. Wan, H. Xu, Z. Li and X. Yang, ACS Appl. Mater. Interfaces, 2016, 8, 30833-30844.

29 Q. Luo, P. Wang, Y. Miao, H. He and X. Tang, Carbohydr. Polym., 2012, 87, 2642-2647.

30 G. Li, Y. Li, Y. Tang, Y. Zhang, Y. Zhang, T. Yin, H. Xu, C. Cai and X. Tang, Int. J. Pharm., 2014, 471, 234-244.

31 G. Li, C. Cai, Y. Qi and X. Tang, Drug Delivery, 2016, 23, 277284.

32 Y. Li, H. Hu, Q. Zhou, Y. Ao, C. Xiao, J. Wan, Y. Wan, H. Xu, Z. Li and X. Yang, ACS Appl. Mater. Interfaces, 2017, 9, 1921519230.

33 Q. Liu, X. Yang, H. Xu, K. Pan and Y. Yang, Eur. Polym. J., 2013, 49, 3522-3529.

34 T. M. Goszczyński, B. Filip-Psurska, K. Kempińska, J. Wietrzyk and J. Boratyński, Pharmacol. Res. Perspect., 2014, 2, e00047.

35 R. P. Feazell, N. Nakayama-Ratchford, H. Dai and S. J. Lippard, J. Am. Chem. Soc., 2007, 129, 8438-8439.

36 P. A. Glover, E. Rudloff and R. Kirby, Journal of Veterinary Emergency and Critical Care, 2014, 24, 642-661.

37 M. Westphal, M. F. M. James, S. Kozek-Langenecker, R. Stocker, B. Guidet and F. H. Van Aken, Anesthesiology, 2009, 111, 187-202.

38 R. Zarychanski, A. M. Abou-Setta, A. F. Turgeon, B. L. Houston, L. McIntyre, J. C. Marshall and D. A. Fergusson, JAMA, J. Am. Med. Assoc., 2013, 309, 678-688.

39 A. Perner, N. Haase, A. B. Guttormsen, J. Tenhunen, G. Klemenzson, A. Aneman, K. R. Madsen, M. H. Moller, J. M. Elkjaer, L. M. Poulsen, A. Bendtsen, R. Winding, M. Steensen, P. Berezowicz, P. Soe-Jensen, M. Bestle, K. Strand, J. Wiis, J. O. White, K. J. Thornberg, L. Quist, J. Nielsen, L. H. Andersen, L. B. Holst, K. Thormar, A.-L. Kjaeldgaard, M. L. Fabritius, F. Mondrup, F. C. Pott, T. P. Moller, P. Winkel, J. Wetterslev, S. T. Grp and T. Scandinavian Critical Care, N. Engl. J. Med., 2012, 367, 124-134.

40 J. A. Myburgh, S. Finfer, R. Bellomo, L. Billot, A. Cass, D. Gattas, P. Glass, J. Lipman, B. Liu, C. McArthur, S. McGuinness, D. Rajbhandari, C. B. Taylor, S. A. R. Webb, C. Investigators and I. Australian New Zealand, N. Engl. J. Med., 2012, 367, 1901-1911.

41 N. Haase, A. Perner, L. I. Hennings, M. Siegemund, B. Lauridsen, M. Wetterslev and J. Wetterslev, Br. Med. J., 2013, 346, 839-851.

42 A. Rolland-Sabate, P. Colonna, M. G. Mendez-Montealvo and V. Planchot, Biomacromolecules, 2007, 8, 2520-2532.

43 H. G. Owen and M. E. Brecher, J. Clin. Apheresis, 1997, 12, 8792.

44 N. Miao, J. Yang, Z. Du, W. Liu, H. Ni, J. Xing, X. Yang, B. Xu and X. Hou, Perfusion, 2014, 29, 462-468.

45 M. Hosseinzadeh Maleki, P. Derakhshan, A. Rahmanian Sharifabad and A. Amouzeshi, Anesthesiology and pain medicine, 2016, 6, e30326.

46 A. Sputtek, E. P. Horn, J. S. A. Esch and P. Kühnl, Anasthesiol Intensivmed Notfallmed Schmerzther, 2001, 36, 162-164.

47 A. Sputtek, P. Kuehnl and A. W. Rowe, Transfus. Med. Hemother., 2007, 34, 262-267. 
48 A. Stolzing, Y. Naaldijk, V. Fedorova and S. Sethe, Transfus. Apher. Sci., 2012, 46, 137-147.

49 H. Wu, H. Hu, J. Wan, Y. Li, Y. Wu, Y. Tang, C. Xiao, H. Xu, X. Yang and Z. Li, Chem. Eng. J., 2018, 349, 129-145.

50 C. D. Taeger, O. Friedrich, C. Drechsler, A. Weigand, F. Hobe, C. I. Geppert, F. Muench, T. Birkholz, R. Buchholz, R. E. Horch and K. Praebst, Clin. Hemorheol. Microcirc., 2016, 64, 91-103.

51 I. O. Szymanski, Vox Sang., 1983, 44, 106-114.

52 J. H. Lee, S. F. Leitman and H. G. Klein, Blood, 1995, 86, 4662-4666.

53 D. R. Ambruso, Transfusion, 2015, 55, 911-918.

54 L. Feng, N. Zhao, X. Yao, X. Sun, L. Du, X. Diao, S. Li and Y. Li, Liver Transpl., 2007, 13, 1125-1136.

55 P. R. Dragsten, P. E. Hallaway, G. J. Hanson, A. E. Berger, B. Bernard and B. E. Hedlund, J. Lab. Clin. Med., 2000, 135, $57-65$.

56 A. Greindl, C. Kessler, B. Breuer, U. Haberl, A. Rybka, M. Emgenbroich, A. J. G. Pötgens and H. G. Frank, Open Hematol. J., 2010, 4, 1-14.

57 C. M. Paleos, Z. Sideratou and D. Tsiourvas, Bioconjugate Chem., 2017, 28, 1611-1624.

58 C. M. Paleos, Z. Sideratou, T. A. Theodossiou and D. Tsiourvas, Chem. Biol. Drug Des., 2015, 85, 653-658.

59 R. Liebner, R. Mathaes, M. Meyer, T. Hey, G. Winter and A. Besheer, Eur. J. Pharm. Biopharm., 2014, 87, 378-385.

60 H. Hu, C. Xiao, H. Wu, Y. Li, Q. Zhou, Y. Tang, C. Yu, X. Yang and Z. Li, ACS Appl. Mater. Interfaces, 2017, 9, 42225-42238.

61 A. Besheer, G. Hause, J. Kressler and K. Maeder, Biomacromolecules, 2007, 8, 359-367.

62 M. Noga, D. Edinger, W. Roedl, E. Wagner, G. Winter and A. Besheer, J. Controlled Release, 2012, 159, 92-103.

63 M. Noga, D. Edinger, R. Kläger, S. V. Wegner, J. P. Spatz, E. Wagner, G. Winter and A. Besheer, Biomaterials, 2013, 34, 2530-2538.

64 D. Narayanan, S. Nair and D. Menon, Int. J. Biol. Macromol., 2015, 74, 575-584.

65 J. Li, Y. Yang, L. Lu, Q. Ma and J. Zhang, Int. J. Nanomed., 2018, 13, 2129-2141.

66 Q. Zhou, Y. Li, Y. Zhu, C. Yu, H. Jia, B. Bao, H. Hu, C. Xiao, J. Zhang, X. Zeng, Y. Wan, H. Xu, Z. Li and X. Yang, J. Controlled Release, 2018, 275, 67-77.
67 H. Hu, J. Wan, X. Huang, Y. Tang, C. Xiao, H. Xu, X. Yang and Z. Li, Nanoscale, 2018, 10, 10514-10527.

68 J. Devy, E. Balasse, H. Kaplan, C. Madoulet and M. C. Andry, Int. J. Pharm., 2006, 307, 194-200.

69 S. Harling, A. Schwoerer, K. Scheibe, R. Daniels and H. Menzel, J. Microencapsulation, 2010, 27, 400-408.

70 G. Baier, D. Baumann, J. M. Siebert, A. Musyanovych, V. Mailaender and K. Landfester, Biomacromolecules, 2012, 13, 2704-2715.

71 B. Kang, P. Okwieka, S. Schoettler, O. Seifert, R. E. Kontermann, K. Pfizenmaier, A. Musyanovych, R. Meyer, M. Diken, U. Sahin, V. Mailaender, F. R. Wurm and K. Landfester, Biomaterials, 2015, 49, 125-134.

72 L. K. Huang, R. C. Mehta and P. P. DeLuca, Pharm. Res., 1997, 14, 475-482.

73 A. D. A. Schwoerer, S. Harling, K. Scheibe, H. Menzel and R. Daniels, Eur. J. Pharm. Biopharm., 2009, 73, 351-356.

74 S. Woehl-Bruhn, A. Bertz, S. Harling, H. Menzel and H. Bunjes, Eur. J. Pharm. Biopharm., 2012, 81, 573-581.

75 S. Woehl-Bruhn, A. Bertz, J. Kuntsche, H. Menzel and H. Bunjes, Eur. J. Pharm. Biopharm., 2013, 85, 1215-1218.

76 S. Hoffmann, H. Caysa, J. Kuntsche, P. Kreideweiss, A. Leimert, T. Mueller and K. Maeder, Carbohydr. Polym., 2013, 95, 404-413.

77 R. Sleightholm, B. Yang, F. Yu, Y. Xie and D. Oupický, Biomacromolecules, 2017, 18, 2247-2257.

78 C. I. Gosch, T. Haase, B. A. Wolf and W. M. Kulicke, Starch/ Staerke, 2002, 54, 375-384.

79 B. Wittgren, K. G. Wahlund, M. Andersson and C. Arfvidsson, Int. J. Polym. Anal. Charact., 2002, 7, 19-40.

80 D. J. Nagy, J. Appl. Polym. Sci., 1996, 62, 845.

81 C. Augsten and K. Maeder, Int. J. Pharm., 2008, 351, 23-30.

82 W. Burchard, Adv. Polym. Sci., 1999, 143, 114-194.

83 H. Takahashi, S.-i. Sawada and K. Akiyoshi, ACS Nano, 2011, 5, 337-345.

84 C. Yu, Q. Zhou, F. Xiao, Y. Li, H. Hu, Y. Wan, Z. Li and X. Yang, ACS Appl. Mater. Interfaces, 2017, 9, 10481-10493.

85 S. Aryal, C.-M. J. Hu and L. Zhang, ACS Nano, 2010, 4, 251258.

86 Y. Tang, Y. Li, R. Xu, S. Li, H. Hu, C. Xiao, H. Wu, L. Zhu, J. Ming, Z. Chu, H. Xu, X. Yang and Z. Li, Nanoscale, 2018, 10, 17265-17274. 